\title{
Discussion on Oboe Teaching and Cultivation of Comprehensive Quality
}

\author{
Yang Zhang* \\ H.S. Skovoroda Kharkiv National Pedagogical University, Kharkiv, Ukraine
}

\begin{abstract}
With the continuous deepening of education reform, more demands are placed on the current teaching. Oboe teaching needs to adapt to the pace of education reform and make certain changes to teaching ideas and methods. While doing basic teaching well, it is necessary to improve the comprehensive quality of students, so that students can meet the needs of social development. Therefore, in teaching, teachers need to innovate existing teaching methods, focus on cultivating students' comprehensive qualities, improve the overall quality of teaching, and ensure that students can achieve comprehensive development.
\end{abstract}

Keywords: Oboe Teaching; Training Comprehensive Quality; Training Methods

In recent years, with the continuous popularization of symphony, people's understanding of music has been continuously improved, and a music learning trend has gradually formed in society. The oboe has been around for hundreds of years, but at present, my country is in the embryonic stage of development. Most people do not understand the oboe, and there is a lack of information in teaching. This has caused many scholars to fail to master the essentials of learning. In teaching, while helping students master basic knowledge, it is necessary to focus on cultivating students with a certain comprehensive quality, so that students can improve their comprehensive quality through learning, and have a wealth of knowledge, which will help students in future study and life.

\section{Oboe playing skills}

\subsection{Breath}

No matter what kind of woodwind instrument, the principle of pronunciation is the same, that is, the player controls the reed with his lips, and gives a certain pressure to make the instrument vibrate to make a sound. For the performance of the oboe, the good and bad playing skills are determined by breathing. Because the whistle of the oboe is narrow and the amount of air passing is relatively small, it is very important to breathe correctly. Generally, abdominal or chest-abdominal styles are used during performance, but some students use chest style to perform. Although this breathing method can also play with sufficient breath, the sound is relatively narrow and sullen.

\subsection{Lips}

The oboe uses a double-envelope shape, that is, when the windman is playing, the correct mouth shape is that the upper and lower teeth need to be separated. The two lips are covered with teeth as a cushion. The lower bala is flat. Put the reed between the lips. The strength of the reed is appropriate. The lips need to maintain a certain elasticity ${ }^{[1]}$. When playing, it is usually emphasized that there is no reed, that is, the length of the tip of the whistle into the lips should be suitable. The advantage of this is that the vibration of the reed is completely within the control range of the lips. The softer the vibration, the softer the tone.

\subsection{Fingering}

The finger movement is mainly controlled by the palm muscles. The finger needs to be raised to the correct height from the hole. It should be performed by relaxing the palm muscles. If you contract the muscles hard to keep the fingers straight, this will cause a certain burden on the back muscles that are not strong enough. When the finger moves up and down continuously, the distance of the finger from the hole is achieved by relaxing the back muscles of the hand and contracting naturally. In this way, the wrist and finger joints caused by excessive contraction of the back muscles when the finger is lifted can be avoided, and the finger is also flexible and relaxed.

Copyright (C) 2020 Yang Zhang

doi: $10.18282 / 1-$ e.v9i4.1743

This is an open-access article distributed under the terms of the Creative Commons Attribution Non-Commercial License (http://creativecommons.org/licenses/by-nc/4.0/), which permits unrestricted non-commercial use, distribution, and reproduction in any medium, provided the original work is properly cited.

Colleges and Universities [J].Higher Education Forum, (2): 8.

[4] Decision of the Central Committee of the Communist Party of China on Several Major Issues Concerning Upholding and Improving the Socialist System with Chinese Characteristics and Promoting the Modernization of the National Governance System and Governance Capacity[N]. People's Daily, 2019-11-5; (1). 


\subsection{Tonguing}

Tongue playing in wind music is usually called voicing, that is, a technique of using the tongue to separate a series of continuous sounds or relatively long sounds into separate parts, and then playing, the purpose of using this technique is mainly to enable the instrument to vibrate at the correct time and emit the required volume ${ }^{[2]}$. In order to get a better tongue effect, in addition to having the correct posture and mouth shape, you also need to enable the tongue to reach the reeds correctly. Because each person's condition is different, the tongue length and thickness are different, so the position used is also different, but no matter which position is used, the tongue must be relaxed to touch the reed, and the action is downward and backward, the action should be small and light. Of course, the smaller the contact area between the tongue and the reed, the better, so that the sound can be spoken more quickly and clearly. It is best for beginners not to learn phonology blindly. Only after all the skills have stabilized, can they try it, otherwise it will be more difficult to change after forming a habit.

\section{Oboe teaching status}

At present, the oboe teaching still adopts a more traditional way, mainly based on the syllabus, and strictly complete the teaching tasks that need to be completed with the course time to achieve the expected teaching goals. When teaching, teachers generally check the students' performance level and ability, as the basis for measuring the teaching effect, and pay attention to the students' playing foundation and theoretical knowledge. Therefore, current teaching focuses on helping students achieve balanced development. This model will cause some students to fail to effectively cultivate their abilities and talents in certain areas. For example, a student's talent and ability when playing are relatively strong, but the theoretical basis is general, which prevents him from obtaining excellent results, because the teacher mainly combines the two aspects to determine the student's performance. In the long run, students tend to devote more time and energy to theoretical knowledge, and their original talents cannot be effectively cultivated, resulting in a waste of resources.

Therefore, in order to help students better adapt to social development, teachers need to reform and innovate existing teaching methods and contents. Firstly, it is necessary to focus on the reliability of teaching content and methods to ensure that teaching can truly cultivate the professional ability of students, and the teaching method needs to put students first in the first place, to ensure that the teaching can contain certain humanistic features, so that students can achieve effective growth and development. Secondly, in the teaching process, teachers need to summarize and analyze the various problems found after class ${ }^{[3]}$. If it is a student's problem, then the teacher needs to correct it in time when a similar situation occurs in the next teaching, if it is the teacher's own problem, the teacher needs to use his spare time to enrich his knowledge, improve professional quality and comprehensive ability, so as to ensure that he can better lead students to learn.

\section{Oboe teaching and comprehensive quality training strategy}

\subsection{Effectively improve students' reaction ability}

When playing the oboe, it is necessary to borrow the coordination and cooperation of the whole body. Therefore, the player needs to have a more sensitive response ability to coordinate and cooperate with multiple organs of the body such as eyes, hands, brain and mouth. The mouth determines the sound quality when playing. If the shape of the mouth used is not standard, it will cause great interference to the performance of the performance. In terms of breathing, the most important thing to note when playing all instruments is breathing. Only by mastering the scientific and correct breathing method can you achieve long-lasting performance. Finally, there is the brain. The brain is mainly responsible for the unified management of all the above human parts to ensure that the performance can have a certain degree of coordination ${ }^{[4]}$.

\subsection{Effectively enhance students' memory}

If you want to play beautiful music, you first need to have a good memory ability, and memorize the content and skills you need to play in order to ensure the integrity of the performance. In actual works there will be a variety of musical rhythms, tones and styles. Therefore, in actual learning, teachers can improve the students' memory ability by asking students to memorize music scores. In the long run, they can effectively improve students' music literacy and comprehensive quality, which have a positive impact on students' music learning and development.

\subsection{Establish a more correct aesthetic concept}

Because the sound of the oboe is very pure, it is often called the little princess in the band. By learning the oboe, students can better feel the beautiful music and bring some beautiful feelings to the students' souls. Because the melody of the music has a strong sense of beauty, the sound and rhythm are very moving ${ }^{[5]}$. In the process of performance, different types and styles of works express different ideas, some works are more delicate, some are more rude, these different emotions can have a certain impact on students' aesthetic concepts. Therefore, learning the oboe is very helpful to cultivate students' sense of rhythm and music. At the same time, it can also help students form a certain musical style and provide support for students' future learning and development.

\subsection{Cultivate students' imagination and practical ability}

In the initial stage of learning the oboe, as in the beginning of learning to write, it needs to be imitated. Once you enter the correct learning track, you need to have certain personal characteristics and innovative capabilities. In the teaching process, teachers need to actively guide students to create, for those students with different ideas, teachers need timely and effective support and encouragement, cannot stifle students' creative ideas ${ }^{[6]}$. Therefore, teachers cannot use the traditional and rigid teaching mode, and cannot instill knowledge into students' minds. They need to actively reflect the main position of students in learning, so that students can truly become the masters of the classroom, so that students can actively participate in learning ${ }^{[7]}$. In this relaxed and pleasant learning atmosphere, students' creative inspiration and ideas will also appear easily. Teachers need to encourage students 
throughout the teaching process to effectively cultivate students' creativity and enhance students' sense of innovation.

\subsection{Enhance students' sense of collective cooperation}

Oboe has many forms in actual performance. Firstly, there is the simplest solo, and secondly, it can be combined with other performance forms to jointly express the emotion and connotation of music, such as polyphony and grand ensemble. If it is an ensemble performance, students need to cooperate with other musicians to achieve effective communication, so as to ensure that the music played is smoother and the emotions expressed are more profound ${ }^{[8]}$. Therefore, it is very necessary to cultivate students with a certain sense of cooperation, students need to have certain communication skills and expression skills to avoid mistakes in the performance process, and they also need to have a collectivism-related spirit to achieve a more perfect performance. In addition, teaching also needs to train students to improve their collaboration skills and concepts through daily practice, to ensure that students can form good ideas and concepts, and to lay a good foundation for their future professional development.

\section{Conclusion}

Music has a very important influence on cultivating people's sentiment. With the help of music, people's emotions can become more colorful and tasteful. Through the study of oboe, the comprehensive ability and quality of students can be effectively improved, so that students can truly achieve comprehensive development. In the teaching process, teachers can help students possess proficient playing skills by using reasonable teaching methods. At the same time, they need to develop students' good reaction ability, memory ability, aesthetic ability, imagination ability and practical ability through various methods. In addition, it can also help students to achieve a comprehensive and balanced development by cultivating students' collective consciousness, and provide help for students'future study and life.

\section{Reference}

[1]Li Wanchun. Discussion on oboe teaching and cultivation of comprehensive quality[J]. Art Science and Technology, 2019; 32(3): 259.

[2]Zhu Di. On oboe teaching and cultivation of comprehensive quality[J]. Northern Music, 2013; (8): 125.

[3]Sheng Longfei. Analysis of the application of oboe in the symphony orchestra and the accomplishment of oboe players[J]. Shenzhou, 2019; (32): 41.

[4]Ren Liang. Analysis of breathing training in oboe learning[J]. The Sound of the Yellow River, 2018; (6): 103.

[5]Song Peng. Common problems and solutions in oboe learning[J]. Grand stage, 2016; (2): 96-97.

[6]Li Huancheng. Obode Performance and Teaching[J]. Literary Life -Wenhai Art Garden, 2015; (3): $236-236$.

[7]Zhao Shangjie. The theory and practice of oboe teaching method[J]. Music Time and Space, 2014; (10): 165-165.

[8]Yang Guang. Development of oboe teaching and performance in China[J]. Art Education, 2012; (009 ): 96. 